\title{
Influence of Polymer Coatings on the Mechanical Properties of Steel Samples in Tensile and Bending Tests
}

\author{
O.A. Pashkov \\ Moscow Aviation Institute (National Research University), Volokolamskoe shosse, 4, 125993, Moscow, Russia \\ oapashkov@mail.ru
}

Article History: Received: 11 January 2021; Accepted: 27 February 2021; Published online: 5 April 2021

\begin{abstract}
An experimental and theoretical study of the effect of polymer coatings on an epoxy-polyester base on the mechanical properties of samples in the form of steel plates has been carried out. It is shown that, despite the fact that the thickness of the coatings is only $100 \mu \mathrm{m}$, they have a significant effect on the mechanical properties of plates up to $1,5 \mathrm{~mm}$ thick, leading to a decrease in Young's modulus, tensile strength and ultimate deformations of the samples. It was shown that the elastic modulus of the coated plate cannot be determined unambiguously from tests for central tension and three-point bending. In bending tests, there is a more significant reduction in plate stiffness compared to tensile tests. This effect is confirmed by calculations within the framework of classical models of the theory of elasticity.
\end{abstract}

Keywords: Strength, Young's modulus, plates, coatings.

\section{Introduction}

Young's modulus is the most important mechanical property of a material and its measurement is of great importance in applied and fundamental fields. In the case of multilayer materials (thin and thick coatings are applied to different substrates)[1-8], which are used in many fields (aerospace, automotive, electronic, etc.)[926], understanding and modeling the mechanical behavior of materials (e.g. practical adhesion, wear, friction, protective properties, also internal stresses) require knowledge of Young's moduli of materials and substrate, and coating [27-35]. As a rule, data on Young's moduli for various materials in their volume form are available from the literature. However, when the same materials are applied to a substrate as thin plates or layers (coatings), the Young's modulus values differ significantly[36-45]. This study aims to determine the Young's modulus of coating materials.

\section{Experimental techniques}

The tests were carried out on specimens in the form of plates $120 \mathrm{~mm}$ long, $12 \mathrm{~mm}$ wide and $0,7 \mathrm{~mm}$ and 1,5 mm thick.. The material of the plates (substrates) is rolled sheet steel of grade 08PS (unalloyed structural steel with a low carbon content). On the surface of the plates, a powder coating on an epoxy-polyester base of the EUROPOLVERI brand (Italy) was applied by electrostatic method. Before applying coatings, preliminary preparation of the steel surface was carried out: degreasing and then phosphating. The coating thickness was 100 $\mu \mathrm{m}$ with a scatter of $\pm 30 \mu \mathrm{m}$. Coating was carried out in a Gema paint booth (Switzerland). Two batches of ten samples were made for tensile and flexural tests. Samples in different batches differed in the thickness of the steel substrate.

Mechanical tests were carried out at room temperature on an Instron 5980 device (UK) with Bluehill 3 software. A contact extensometer with a base of $25 \mathrm{~mm}$ was used to measure tensile deformations of the samples. The length of the working part of the sample was $80 \mathrm{~mm}$. Tensile tests were carried out at a speed of $1 \mathrm{~mm} / \mathrm{min}$ at the linear stage of sample deformation and at a speed of $2 \mathrm{~mm} / \mathrm{min}$ after removing the extensometer at the stage of plastic deformation and fracture. The tensile tests were used to determine the elastic modulus and ultimate strength of the samples.

In the three-point bending test, the support spacing was $80 \mathrm{~mm}$. To accurately measure the displacements of the plate, a contact extensometer with a base of $25 \mathrm{~mm}$ was used, which was attached to a deflectometer installed in the center under the sample. Bending tests were carried out up to the maximum value of displacement of the sample center point $-1,2 \mathrm{~mm}$. The flexural modulus of the plates $\mathrm{E}$ was determined as a result of the flexural tests. The calculation formula in the Bluehill 3 software corresponds to the standard expression for three-point bending:

$$
E=\frac{L^{3} \cdot F}{4 b h^{3} \cdot w}
$$

where L - distance between supports, $\mathrm{F}$ - active force, bandh - sample width and thickness, w - moving sample midpoint.

The program automatically selected the most typical interval on the stress-strain diagram to determine the elastic modulus of the samples. 


\section{Flexural test results}

Figures 1 and 2 show the obtained strain-stress diagrams in bending tests for the test specimens without epoxy coatings (Fig. 1) and with coatings (Fig. 2). A summary of the test results is presented in the table1.

The graphs along the $\mathrm{X}$ axis show the deformation values on the lower surface of the samples (these are tensile deformations in bending), calculated from the known displacement values in the middle of the samples under the action of a load:

$$
\varepsilon=\frac{6 \cdot w \cdot h_{0}}{L}
$$

To plot the diagram, the stresses were determined automatically by the formula:

$$
\sigma=\frac{3 L P}{2 b h_{0}{ }^{2}}
$$

Bending tests were carried out within the elastic deformation zone of the samples. The value of the modulus of elasticity was determined automatically, while the angle of inclination of the diagram used in the calculations in the figures is shown by thin straight lines of the corresponding color.

The diagrams contain a characteristic horizontal part of the graphs at the beginning of the test, which arises due to the presence of gaps between the sample lying on the supports and the deflectometer installed under the sample. For thin samples, "noises" appear on the diagrams, which are associated with insufficient accuracy of the used setup. However, judging by the scatter of the obtained experimental values (less than 15\%), all test results can be considered reliable, with the exception of $0,7 \mathrm{~mm}$ thick samples with coatings, for which a scatter of $23 \%$ was obtained. Experimenting with such thin coated samples requires additional verification on a facility with a higher precision in voltage measurement.
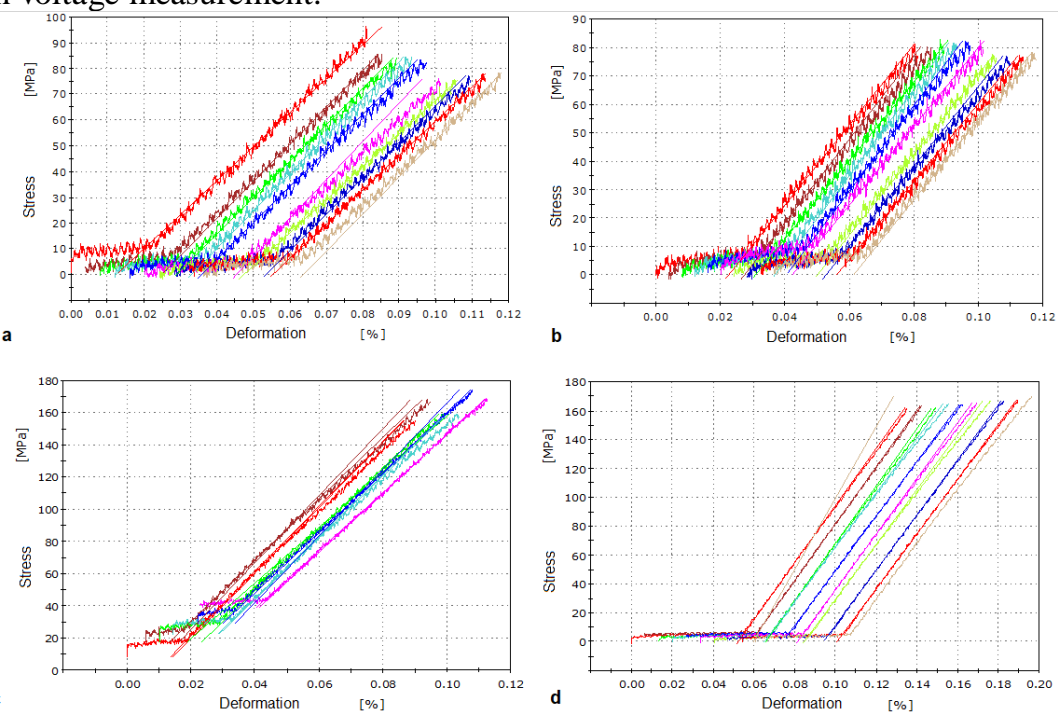

Fig. 1. Results of bending tests of uncoated steel samples.

a) $\mathrm{h}_{\mathrm{cr}}=0,7 \mathrm{~mm}$; b) $\mathrm{h}_{\mathrm{cr}}=0,9 \mathrm{~mm}$; c) $\mathrm{h}_{\mathrm{cr}}=1,2 \mathrm{~mm}$; d) $\mathrm{h}_{\mathrm{cr}}=1,5 \mathrm{~mm}$.
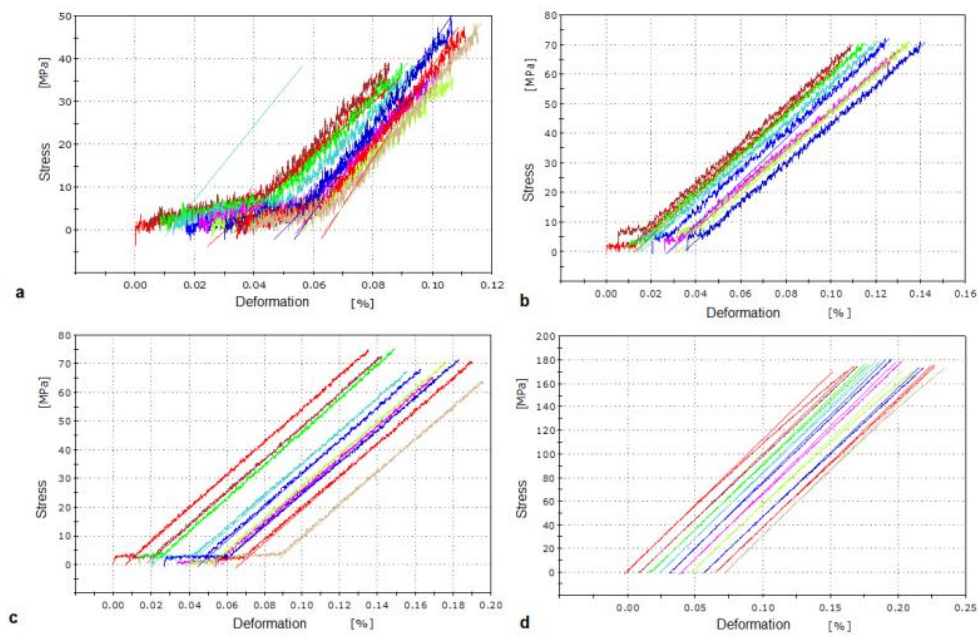

Fig. 2. Results of bending tests on steel specimens with epoxy coatings, $130 \mu \mathrm{m}$ thick. a) hst $=0,7 \mathrm{~mm} ; \mathrm{b}) \mathrm{hst}=$ $0,9 \mathrm{~mm}$; c) hst $=1,2 \mathrm{~mm}$; d) hst $=1,5 \mathrm{~mm}$. 
Table 1. Results of bending tests.

\begin{tabular}{|l|l|l|l|l|}
\hline \multirow{2}{*}{$\begin{array}{l}\text { Bending of uncoated } \\
\text { specimens }\end{array}$} & $\begin{array}{l}h_{c m}, \\
\mathrm{~mm}\end{array}$ & $\begin{array}{l}\mathrm{E}, \mathrm{GPa} \\
(\text { mean) }\end{array}$ & $\begin{array}{l}\text { Standard } \\
\text { deviation, GPa }\end{array}$ & $\begin{array}{l}\text { The coefficient of } \\
\text { variation, \% }\end{array}$ \\
\cline { 2 - 5 } & 0,7 & 193 & 15 & 7,7 \\
\cline { 2 - 6 } & 0,9 & 191 & 5,7 & 3 \\
\cline { 2 - 6 } & 1,2 & 190 & 6 & 3,2 \\
\hline \multirow{2}{*}{$\begin{array}{l}\text { Bending epoxy coated } \\
\text { specimens }\end{array}$} & 1,5 & 192 & 3 & 1,6 \\
\cline { 2 - 6 } & 0,7 & 154 & 8,6 & 23 \\
\cline { 2 - 6 } & 1,2 & 136 & 5,8 & 11,5 \\
\cline { 2 - 5 } & 1,5 & 202 & 1,5 & 9,6 \\
\hline
\end{tabular}

\section{Tensile test results}

Figures 3 and 4 show the obtained strain-stress diagrams for the test specimens in tensile tests.

Figure 3a below shows the tensile diagram of a steel specimen under single loading until failure. The initial $\boldsymbol{O A}$ site obeys Hooke's law: $\sigma=E \cdot \mathcal{E}$.At point $\boldsymbol{A}$ of the diagram, Hooke's law is violated: the relationship between force and elongation becomes nonlinear. The diagram shows a horizontal section (section $\boldsymbol{B C}$ ), called the yield area. At this stage of the test, the sample is elongated (deformed) at a practically constant force. This phenomenon is called fluidity, while the sample is deformed evenly and along the entire length of the working part. At point $\boldsymbol{C}$ the yield platform ends and the hardening section begins. At the end point $\boldsymbol{D}$ of this section, the maximum force that the sample can withstand is reached. Stress state of the sample up to point $\boldsymbol{D}$ - uniaxial. Further, a section of destruction or a section of local fluidity begins. It is characterized by local thinning of the specimen and the appearance of a neck. In the final section $\boldsymbol{D E}$ (after the neck appears), deformations are localized in the neck; in the rest of the sample, they practically do not increase. The deformation in the neck is inhomogeneous and has a significant gradient along the sample axis. The stress state in this area becomes inhomogeneous, in addition, it changes qualitatively - it becomes triaxial. The diameter of the neck decreases as the specimen deforms, and the specimen breaks along the smallest section of the neck.
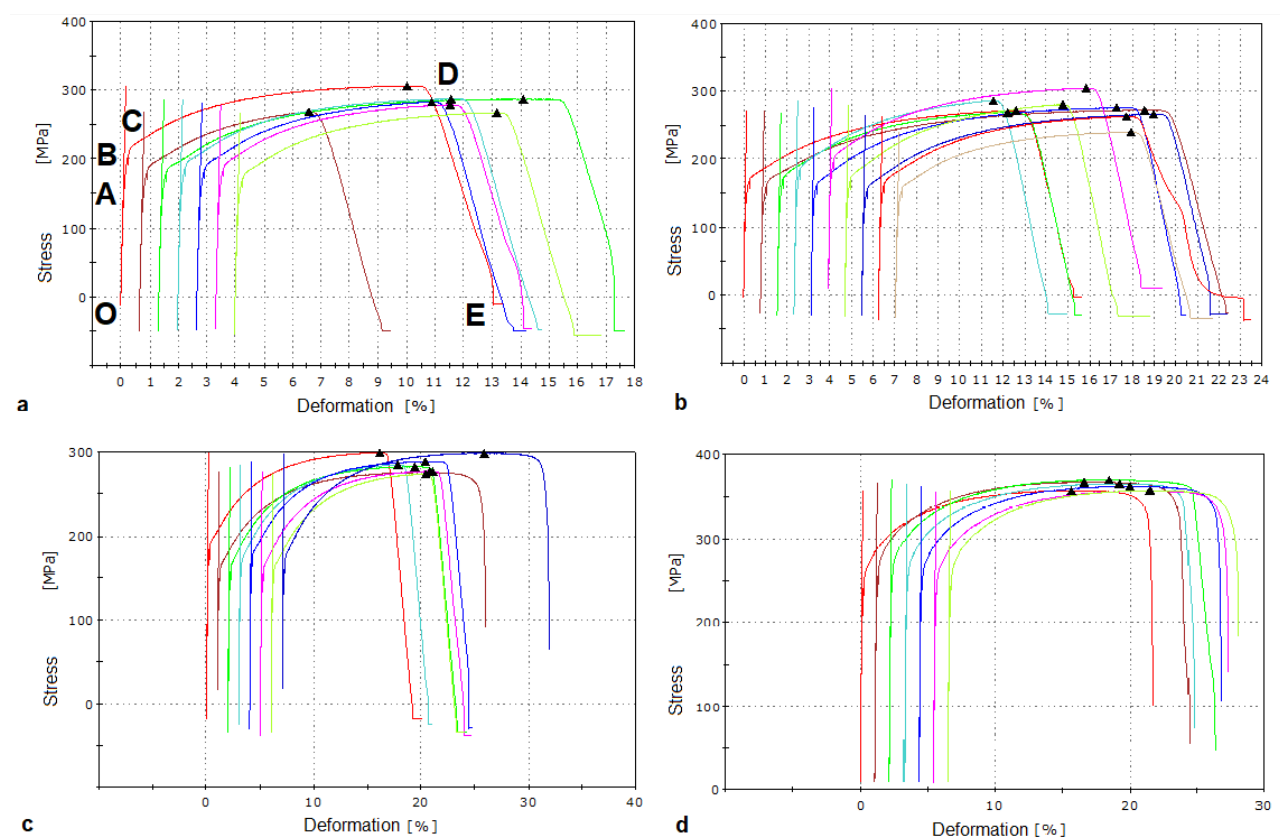

Fig. 3. Results of tensile tests on steel samples without coating. a) $\mathrm{h}_{\mathrm{cr}}=0,7 \mathrm{~mm}$; b) $\mathrm{h}_{\mathrm{cr}}=0,9 \mathrm{~mm}$; c) $\mathrm{h}_{\mathrm{cr}}=1,2 \mathrm{~mm}$; d) $\mathrm{h}_{\mathrm{cr}}=1,5 \mathrm{~mm}$. 

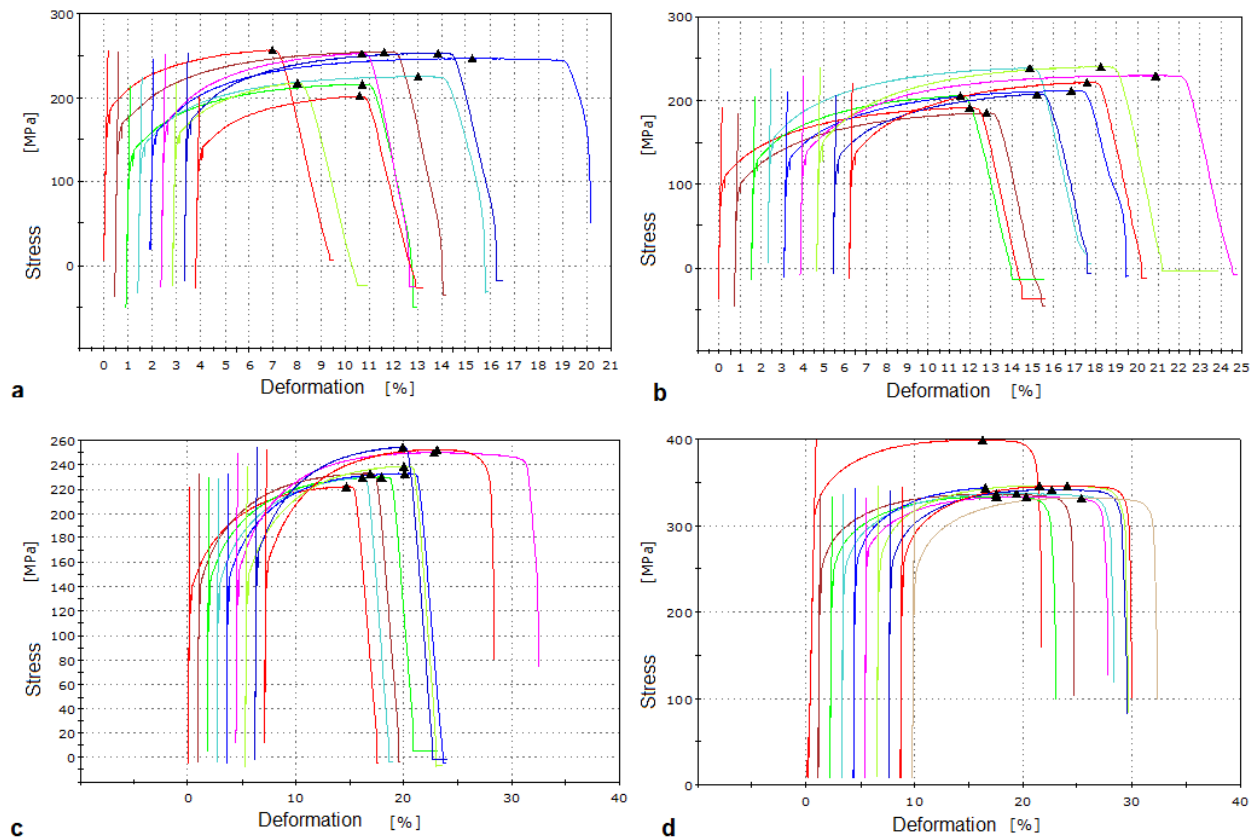

Fig. 4. Results of tensile tests on steel samples with epoxy coatings, $130 \mu \mathrm{m}$ thick. a) $\mathrm{h}_{\mathrm{cr}}=0,7 \mathrm{~mm}$; b) $\mathrm{h}_{\mathrm{cT}}=0,9 \mathrm{~mm}$; c) $\mathrm{h}_{\mathrm{cr}}=1,2 \mathrm{~mm}$; d) $\mathrm{h}_{\mathrm{cT}}=1,5 \mathrm{~mm}$.

Table 2. Tensile test results.

\begin{tabular}{|l|l|l|l|l|}
\hline & $h_{c m}, \mathrm{~mm}$ & $\begin{array}{l}\text { Young's modulus, GPa } \\
\text { (mean value) }\end{array}$ & $\begin{array}{l}\text { Maximum load, } \\
\mathrm{kgf}\end{array}$ & $\begin{array}{l}\text { Ultimate strength, } \\
\mathrm{MPa}\end{array}$ \\
\hline \multirow{2}{*}{$\begin{array}{l}\text { Stretching uncoated } \\
\text { specimens }\end{array}$} & 0,7 & 163 & 0,23 & 283 \\
\cline { 2 - 5 } & 0,9 & 174 & 0,27 & 273 \\
\cline { 2 - 5 } & 1,2 & 180 & 0,36 & 285 \\
\cline { 2 - 5 } & 1,5 & 192 & 0,68 & 362 \\
\hline \multirow{3}{*}{$\begin{array}{l}\text { Stretching epoxy } \\
\text { coated specimens }\end{array}$} & 0,7 & 156 & 0,25 & 236 \\
\cline { 2 - 5 } & 0,9 & 143 & 0,29 & 214 \\
\cline { 2 - 5 } & 1,2 & 152 & 0,4 & 238 \\
\cline { 2 - 5 } & 1,5 & 196 & 0,74 & 339 \\
\hline
\end{tabular}

\section{Analysis of experimental data}

A typical form of stress-strain diagrams for tensile and bending tests of specimens with a thickness of $1,5 \mathrm{~mm}$ and $0,7 \mathrm{~mm}$ with coatings is shown in Figure 5. Figures $5 \mathrm{c}$ and $5 \mathrm{~d}$ show a stress-strain diagram on the surface of the specimen, which is subjected to tensile bending. The test results are presented in table 3 .

It was found that the elastic modulus of coated plates in tension and bending is lower than the standard Young's modulus of the steel grade used $(190 \mathrm{GPa})$. At the same time, in bending tests, the value of the identified elastic modulus of all samples turned out to be lower compared to the value obtained in tensile tests. Also, the value of the elastic modulus of a coated sample depends on the thickness of the steel substrate - thin samples have a lower elastic modulus. The tensile strength of both batches of samples also decreases and amounts to $336 \mathrm{MPa}$ and 236 MPa (Fig. 5a, 5b), compared with the typical characteristic of the steel used - $350 \mathrm{MPa}$. Ultimate deformations of specimens in tensile tests are reduced by more than three times. The listed effects can be explained by the influence of polymer coatings.

For thin specimens, a significant scatter of values was obtained, especially when determining the elastic modulus in bending tests (22\%), which is associated with insufficient sensitivity of the equipment used (see Fig.5c). The presence of an initial flat, almost horizontal section in the diagram shown in Fig. 5c, due to the fact that there is a small gap between the deflectometer and the sample lying on the supports before testing, which is difficult to eliminate manually if the samples are thin and pliable. The presence of a small jump in deformations in the zone of transition from the linear to the plastic part of the diagram in Figures $5 \mathrm{a}$ and $5 \mathrm{~b}$ is due to the fact that at these points the extensometer was removed from the sample and further measurement of deformations was carried out according to the displacements of the traverse. 

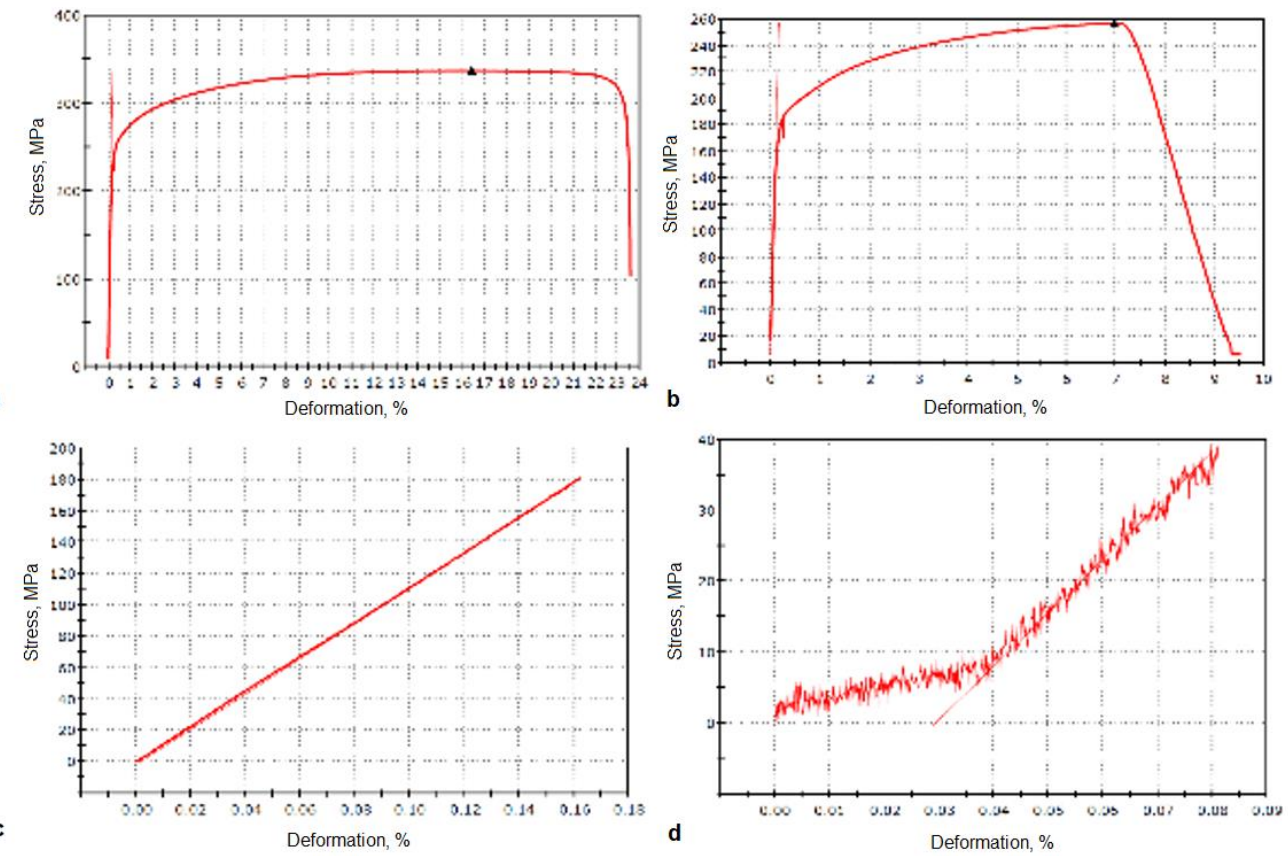

Fig. 5. Typical stress-strain diagrams obtained during tensile and bending tests of steel specimens $1.5 \mathrm{~mm}$ and $0.7 \mathrm{~mm}$ thick with polymer coatings $100 \mu \mathrm{m}$ thick. a) Stretching, 1,5 mm. b) Stretching, 0,7 mm. c) Bend, 1,5 mm. d) Bend, 0,7 mm.

Table 3. Results of tensile and bending tests (the standard deviation is indicated in parentheses).

\begin{tabular}{|l|l|l|l|}
\hline Samples & $\begin{array}{l}\text { Elastic modulus under } \\
\text { tension, GPa }\end{array}$ & $\begin{array}{l}\text { Flexural modulus } \\
\text { bending, GPa }\end{array}$ & $\begin{array}{l}\text { Tensile strength under } \\
\text { tension, MPa }\end{array}$ \\
\hline $\begin{array}{l}\text { Steel specimens } 1,5 \mathrm{~mm} \\
\text { thick coated }\end{array}$ & $169(12)$ & $124(10)$ & $336(5)$ \\
\hline $\begin{array}{l}\text { Coated steel specimens } \\
0,7 \mathrm{~mm} \text { thick }\end{array}$ & $150(13)$ & $85(19)$ & $236(20)$ \\
\hline
\end{tabular}

\section{Conclusion}

The paper reports the problem of changing the mechanical properties of steel plates, on the surface of which protective epoxy coatings are applied. Providing protection against corrosion, polymer coatings lead to a decrease in mechanical samples. The modulus of elasticity of plates with a thickness of $1,5 \mathrm{~mm}$ with a thickness of 100 microns can decrease by more than $10 \%$ in tensile tests and by more than $20 \%$ in bending tests. The elastic moduli of $0,7 \mathrm{~mm}$ thick plates are reduced by more than $20 \%$ and $40 \%$, respectively, in tensile and bending tests. The tensile strength and ultimate deformations of coated samples also decrease. The ambiguity of the determined experimental values of the elastic modulus of plates with coatings follows directly from calculations within the framework of classical models of the theory of elasticity.

\section{References}

1. Astapov, A.N., Lifanov, I.P., Rabinskiy, L.N. Perspective Heat-Resistant Coating for Protection of Cf/SiC Composites in Air Plasma Hypersonic Flow//High Temperature, 2019, 57(5), p. 744-752.

2. Rabinskiy, L.N., Sitnikov, S.A. Development of technologies for obtaining composite material based on silicone binder for its further use in space electric rocket engines// Periodico Tche Quimica, 2018, 15(Special Issue 1), p. 390-395.

3. N.A. Bulychev, A.V. Ivanov. Nanostructure of Organic-Inorganic Composite Materials Based on Polymer Hydrogels, International Journal of Nanotechnology, 2019, Vol. 16, Nos. 6/7/8/9/10, pp. $344-$ 355.

4. N.A. Bulychev, A.V. Ivanov. Study of Nanostructure of Polymer Adsorption Layers on the Particles Surface of Titanium Dioxide, International Journal of Nanotechnology, 2019, Vol. 16, Nos. 6/7/8/9/10, pp. $356-365$.

5. O.A. Butusova. Surface Modification of Titanium Dioxide Microparticles Under Ultrasonic Treatment, International Journal of Pharmaceutical Research, 2020, Vol. 12, I. 4, pp. 2292-2296.

6. A.N. Tarasova. Vibration-based Method for Mechanochemical Coating Metallic Surfaces, International Journal of Pharmaceutical Research, 2020, Vol. 12, Supplementary Issue 2, pp. 1160-1168. 
7. M.O. Kaptakov. Effect of Ultrasonic Treatment on Stability of TiO2 Aqueous Dispersions in Presence of Water-Soluble Polymers, International Journal of Pharmaceutical Research, 2020, Vol. 12, Supplementary Issue 2, pp. 1821-1824.

8. O.A. Butusova. Stabilization of Carbon Microparticles by High-Molecular Surfactants, International Journal of Pharmaceutical Research, 2020, Vol. 12, Supplementary Issue 2, pp. 1147-1151.

9. Yu.V. Ioni. Synthesis of Metal Oxide Nanoparticles and Formation of Nanostructured Layers on Surfaces under Ultrasonic Vibrations, International Journal of Pharmaceutical Research, 2020, Vol. 12, Issue 4, pp. 3432-3435.

10. Astapov, A.N., Kuznetsova, E.L., Rabinskiy, L.N. Operating capacity of anti-oxidizing coating in hypersonic flows of air plasma//Surface Review and Letters, 2019, 26(2), 1850145 p.

11. B.A. Garibyan. Mechanical Properties of Electroconductive Ceramics, International Journal of Pharmaceutical Research, 2020, Vol. 12, Supplementary Issue 2, pp. 1825-1828.

12. B.A. Garibyan. Enhancement of Mechanical Properties of Inorganic Glass under Ultrasonic Treatment, International Journal of Pharmaceutical Research, 2020, Vol. 12, Supplementary Issue 2, pp. 1829-1832.

13. N.A. Bulychev, A.V. Ivanov. Effect of vibration on structure and properties of polymeric membranes, International Journal of Nanotechnology, 2019, Vol. 16, Nos. 6/7/8/9/10, pp. $334-343$.

14. Bulychev N. A., Kuznetsova E.L., Bodryshev V. V.Rabinskiy L.N. Nanotechnological aspects of temperature-dependent decomposition of polymer solutions, Nanoscience and Technology: An International Journal, 2018, Vol. 9 (2), p.91-97.

15. O.A. Butusova. Vinyl Ether Copolymers as Stabilizers of Carbon Black Suspensions, International Journal of Pharmaceutical Research, 2020, Vol. 12, Supplementary Issue 2, pp. 1152-1155.

16. O.A. Butusova. Adsorption Behaviour of Ethylhydroxyethyl Cellulose on the Surface of Microparticles of Titanium and Ferrous Oxides, International Journal of Pharmaceutical Research, 2020, Vol. 12, Supplementary Issue 2, pp. 1156-1159.

17. A.N. Tarasova. Effect of Reagent Concentrations on Equilibria in Water-Soluble Complexes, International Journal of Pharmaceutical Research, 2020, Vol. 12, Supplementary Issue 2, pp. 1169-1172.

18. Bulychev, N.A., Rabinskiy, L.N. Ceramic nanostructures obtained by acoustoplasma technique//Nanoscience and Technology: An International Journal, 2019, 10(3), p. 279-286.

19. A.N. Tarasova. Effect of Vibration on Physical Properties of Polymeric Latexes, International Journal of Pharmaceutical Research, 2020, Vol. 12, Supplementary Issue 2, pp. 1173-1180.

20. B.A. Garibyan. Modelling of Technical Parameters of Discharge Reactor for Polymer Treatment, International Journal of Pharmaceutical Research, 2020, Vol. 12, Supplementary Issue 2, pp. 1833-1837.

21. Yu.V. Ioni, A. Ethiraj. Study of Microparticles Surface Modification by Electrokinetic Potential Measuring, International Journal of Pharmaceutical Research, 2020, Vol. 12, Issue 4, pp. 3436-3439.

22. Bulychev, N.A., Rabinskiy, L.N., Tushavina, O.V. Effect of intense mechanical vibration of ultrasonic frequency on thermal unstable low-temperature plasma// Nanoscience and Technology: An International Journal, 2020, 11(1), p. 15-21.

23. Yu.V. Ioni. Effect of Ultrasonic Treatment on Properties of Aqueous Dispersions of Inorganic and Organic Particles in Presence of Water-Soluble Polymers, International Journal of Pharmaceutical Research, 2020, Vol. 12, Issue 4, pp. 3440-3442.

24. N.A. Bulychev, M.A. Kazaryan. Optical Properties of Zinc Oxide Nanoparticles Synthesized in Plasma Discharge in Liquid under Ultrasonic Cavitation, Proceedings of SPIE, 2019, Vol. 11322, article number 1132219.

25. Yu.V. Ioni, A. Ethiraj. New Tailor-Made Polymer Stabilizers for Aqueous Dispersions of Hydrophobic Carbon Nanoparticles, International Journal of Pharmaceutical Research, 2020, Vol. 12, Issue 4, pp. 3443-3446.

26. Yu.V. Ioni. Nanoparticles of noble metals on the surface of graphene flakes, Periodico Tche Quimica, 2020, Vol. 17, No. 36, pp. 1199-1211.

27. Formalev, V.F., Kartashov, É.M., Kolesnik, S.A. On the Dynamics of Motion and Reflection of Temperature Solitons in Wave Heat Transfer in Limited Regions // Journal of Engineering Physics and Thermophysics, 2020, 93(1), p. 10-15.

28. Formalev, V.F., Bulychev, N.A., Kuznetsova, E.L., Kolesnik, S.A. The Thermal State of a Packet of Cooled Microrocket Gas-Dynamic Lasers // Technical Physics Letters, 2020, 46(3), p. 245-248.

29. Rabinskiy, L.N., Tushavina, O.V., Formalev, V.F. Mathematical modeling of heat and mass transfer in shock layer on dimmed bodies at aerodynamic heating of aircraft// Asia Life Sciences, 2019, (2), p. 897911.

30. Antufev, B.A., Egorova, O.V., Rabinskiy, L.N. Quasi-static stability of a ribbed shell interacting with moving load// INCAS Bulletin, 2019, 11, p. 33-39.

31. Bodryshev, V.V., Babaytsev, A.V., Rabinskiy, L.N. Investigation of processes of deformation of plastic materials with the help of digital image processing// Periodico Tche Quimica, 2019, 16(33), p. 865-876.

32. Rabinskiy, L.N., Tushavina, O.V., Starovoitov, E.I. Study of thermal effects of electromagnetic radiation on the environment from space rocket activity // INCAS Bulletin, 2020, 12(Special Issue), p. 141-148. 
33. Babaytsev, A.V., Orekhov, A.A., Rabinskiy, L.N. Properties and microstructure of AlSi10Mg samples obtained by selective laser melting// Nanoscience and Technology: An International Journal, 2020, 11(3), p. 213-222.

34. Egorova, O.V., Kyaw, Y.K. Solution of inverse non-stationary boundary value problems of diffraction of plane pressure wave on convex surfaces based on analytical solution//Journal of Applied Engineering Science, 2020, 18(4), p. 676-680.

35. Formalev, V.F., Kolesnik, S.A., Garibyan, B.A. Mathematical modeling of heat transfer in anisotropic plate with internal sinks // AIP Conference Proceedings, 2019, 2181, 020003.

36. Formalev, V.F., Kolesnik, S.A., Garibyan, B.A. Heat transfer with absorption in anisotropic thermal protection of high-temperature products // Herald of the Bauman Moscow State Technical University, Series Natural Sciences, 2019, (5), p. 35-49.

37. Kolesnik, S.A., Bulychev, N.A. Numerical analytic method for solving the inverse coefficient problem of heat conduction in anisotropic half-space// Journal of Physics: Conference Series, 2020, 1474(1), 012024.

38. Formalev, V.F., Bulychev, N.A., Kolesnik, S.A., Kazaryan, M.A. Thermal state of the package of cooled gas-dynamic microlasers // Proceedings of SPIE - The International Society for Optical Engineering, 2019, 11322, article number 113221B.

39. Formalev, V.F., Kolesnik, S.A., Garibyan, B.A. Analytical solution of the problem of conjugate heat transfer between a gasdynamic boundary layer and anisotropic strip //Herald of the Bauman Moscow State Technical University, Series Natural Sciences, 2020, 5(92), p. 44-59.

40. Sun, Y., Kolesnik, S.A., Kuznetsova, E.L. Mathematical modeling of coupled heat transfer on cooled gas turbine blades // INCAS Bulletin, 2020, 12(Special Issue), p. 193-200.

41. Kurchatov, I., Bulychev, N., Kolesnik, S., Muravev, E. Application of the direct matrix analysis method for calculating the parameters of the luminescence spectra of the iron ion in zinc sulfide crystals // AIP Conference Proceedings, 2019, 2181, 020015.

42. Antufev, B.A., Kuznetsova, E.L., Rabinskiy, L.N., Tushavina, O.V. Investigation of a complex stressstrain state of a cylindrical shell with a dynamically collapsing internal elastic base under the influence of temperature fields of various physical nature//Asia Life Sciences, 2019, (2), p. 689-696.

43. Antufev, B.A., Kuznetsova, E.L., Rabinskiy, L.N., Tushavina, O.V. Complex stressed deformed state of a cylindrical shell with a dynamically destructive internal elastic base under the action of temperature fields of various physical nature// Asia Life Sciences, 2019, (2), p. 775-782.

44. Rabinskiy, L.N., Tushavina, O.V. Problems of land reclamation and heat protection of biological objects against contamination by the aviation and rocket launch site // Journal of Environmental Management and Tourism, 2019, 10(5), p. 967-973.

45. Dobryanskiy, V.N., Rabinskiy, L.N., Tushavina, O.V. Validation of methodology for modeling effects of loss of stability in thin-walled parts manufactured using SLM technology // Periodico Tche Quimica, 2019, 16(33), p. 650-656. 